\title{
Correction to: Effects of nitrogen supplementation on bioconversion of potato waste by rumen fluid from slaughterhouses to produce eco-friendly products
}

\author{
Saeid Narimani Gharajeh ${ }^{1}$. Jamal Seifdavati ${ }^{1} \cdot$ Hossein Abdi-Benemar ${ }^{1} \cdot$ Abdelfattah Z. M. Salem $^{2}$. \\ Mona M. M. Y. Elghandour ${ }^{2} \cdot$ Reza Seyed Sharifi $^{1}$ \\ (c) Springer-Verlag GmbH Germany, part of Springer Nature 2021
}

Correction to: Biomass Conversion and Biorefinery https://doi.org/10.1007/s13399-021-02037-0

In section 2.5 Statistical analysis, redundant data on lines 7 and 8 must be removed.

The original article has been corrected.

Publisher's note Springer Nature remains neutral with regard to jurisdictional claims in published maps and institutional affiliations.

The original article can be found online at https://doi.org/10.1007/ s13399-021-02037-0.

Abdelfattah Z. M. Salem

salem@uaemex.mx; asalem70@yahoo.com

1 Department of Animal Sciences, Faculty of Agriculture and Natural Resources, University of Mohaghegh Ardabili, Ardabil, Iran

2 Facultad de Medicina Veterinaria Y Zootecnia, Universidad Autónoma del Estado de México, Toluca, Mexico 